Language Variation and Change, 33 (2021), 245-266.

(c) The Author(s), 2021. Published by Cambridge University Press 0954-3945/21 $\$ 16.00$

This is an Open Access article, distributed under the terms of the Creative Commons Attribution-

NonCommercial-ShareAlike licence (http://creativecommons.org/licenses/by-nc-sa/4.0/), which permits non-commercial re-use, distribution, and reproduction in any medium, provided the same Creative Commons licence is included and the original work is properly cited. The written permission of Cambridge University Press must be obtained for commercial re-use.

doi:10.1017/S0954394521000090

\title{
Gender separation and the speech community: Rhoticity in early 20th century Southland New Zealand English
}

\author{
DAN VILLARREAL \\ University of Pittsburgh \\ Lynn Clark, Jennifer Hay and Kevin Watson \\ New Zealand Institute of Language, Brain and Behaviour \\ University of Canterbury
}

A B S T R A C T

The existence of a shared constraint hierarchy is one of the criteria that defines and delimits speech communities. In particular, women and men are thought to differ only in their rates of variable usage, not in the constraints governing their variation; that is, women and men are typically considered to belong to the same speech community. We find that in early twentieth century Southland, New Zealand, women and men had different constraint hierarchies for rhoticity, with a community grammar of rhoticity only developing later. These results may be a product of a particular set of sociohistorical facts thatare not peculiar to Southland. We suggest that further research in other geographical locations may indeed reveal that men and women have different constraint hierarchies for other variables. Speech communities may thus be delimited along social lines in ways that have not been previously considered.

The predominant approach to the speech community in variationist sociolinguistics examines linguistic variables, and in particular the constraints (internal and external conditioning factors, Labov, 1994, 2001) that influence speakers' use of variants. As just one example, a long literature on English coronal stop deletion has found a variety of constraints across communities, with different speech communities exhibiting different constraint hierarchies. For instance, among Southern working-class African American English speakers, the phonological environment of the coronal stop has a greater effect on deletion rates than its morphological status. That is, the phonological environment constraint is weighted more strongly, or is placed higher up the constraint hierarchy, than morphological status in this community. Among working-class Appalachian English speakers, however, the order of these constraints is reversed (Wolfram \& Schilling-Estes, 2006:181). Modern sociolinguistic research often assumes the untested hypothesis that the existence of a shared constraint hierarchy, which is akin to a community grammar, is one of the criteria that defines and delimits 
speech communities (Bayley \& Villarreal, 2019:212; Blaxter, Beeching, Coates, Murphy, \& Robinson, 2019:92; Clark \& Watson, 2016:58; Forrest, 2015:401; Labov, 2007:346; Meyerhoff \& Walker, 2007:359-60; Tamminga, MacKenzie, \& Embick, 2016:307). In the present paper, we refer to this idea as the Speech Community as Shared Constraints Hypothesis ("SCSC" for short). Importantly, the constraints on a variable are typically considered separately from the rates at which variants are used. This means, for example, that a speech community includes individuals who share constraint hierarchies for coronal stop deletion despite having different overall rates of deletion.

Among the various external constraints on sociolinguistic variation (which include interspeaker characteristics such as region, ethnicity, and group membership, and intraspeaker variation such as style, persona, and topic), a wealth of research has consistently found gender to strongly influence sociolinguistic variation (Cheshire, 2004; Labov, 1990, 2001). Yet while it is commonplace to hypothesize that different community grammars may distinguish speakers who differ by social factors such as ethnicity (e.g., Bayley \& Villarreal, 2019:212), sociolinguistic research assumes that women and men are differentiated only in their rates of variable usage, not in the constraints governing their variation. That is, in a given region, women and men are typically considered to belong to the same speech community. The present study presents an analysis of a variable and a speech community, rhoticity in Southland New Zealand English (SldE), that paints a somewhat different picture. We find that SldE did not develop a community grammar of rhoticity until the latter half of the twentieth century, as early twentieth century Southland women and men had different constraint hierarchies for rhoticity. Eventually, women and men converged toward a hierarchy that mostly (but not entirely) mirrored women's earlier patterns. We find possible explanations for the genesis of this differentiation of women's and men's grammars of rhoticity in sociohistorical facts about the construction of gender and in limited contact between men and women in twentieth century Southland. As the broad characteristics of this social context are not likely to be unique to Southland, we would be surprised if interactions between gender and internal constraints are not found in other communities, either in the past or in the present day. These findings suggest that it may indeed be possible for speech communities to be delimited by gender, and so for multiple speech communities to co-exist within the same geographical space in ways that have previously only been described for different ethnic groups in the same geographical space.

Current theory in language variation and change assumes the Speech Community as Shared Constraints Hypothesis (SCSC): the hypothesis that the existence of a community grammar defines and delimits speech communities. This hypothesis was not originally part of variationist study, however. Labov's original definition 
of the speech community made no mention of internal constraints, instead describing New York City as "united by a common evaluation of the same variables which differentiate the speakers" (Labov, 2006/1966:82), with "evaluative norms" determined via subjective evaluation tests and analysis of style-shifting patterns. Indeed, Social stratification of English in New York City engaged with internal constraints in only a limited fashion, instead focusing on the effects of style, gender, social class, age, and ethnicity. The study of internal constraints began in earnest shortly thereafter, spurred by the twin developments of the variable rule formalism and the Varbrul program for performing multivariate analysis of binomial linguistic data (Cedergren \& Sankoff, 1974; Sankoff \& Labov, 1979; Weinreich, Labov, \& Herzog, 1968). In an early paper, Sankoff and Labov (1979:202-3) rejected the idea that shared internal constraints define the speech community: "We know that every speaker is a member of many nested and intersecting speech communities...Even on the level of speech production no user of variable rules has claimed, implicitly or explicitly, that a single rule per variable is always capable of accounting for the 'orderly heterogeneity' characteristic of a speech community." To that end, Sankoff and Labov reported on a speaker-clustering algorithm that was included in an early version of Varbrul, such that ad hoc groups within a speech community could have different variable rules; however, this clustering algorithm appears to never have gained currency in variationist methodological practice.

Despite Sankoff and Labov's statements, SCSC became mainstream largely thanks to Guy's (1980) finding that individual speakers' deviance from the community's constraint rankings decreased in frequency as token counts increased (in particular, speakers' token counts per "cell," or factor level). This finding reduced the problem of variability in constraint grammars between members of a speech community to a problem of insufficient data: "speakers have essentially identical norms for final /t,d/ deletion, and...one only needs to obtain large amounts of data to demonstrate this fact" (Guy, 1980:30; emphasis added). (Note that "norms" is no longer the "evaluative norms" of Labov (2006:82 [1966]) but instead refers to the effect of constraints on variation.) This original finding has been refined by subsequent work, as in Forrest's (2015) finding that, despite a period of intergenerational social change in Raleigh, North Carolina, in apparent time speakers' lexical category constraint for (ing) maintained a stable ranking of levels. Indeed, it is not uncommon to see disjunctive definitions of the speech community that reflect SCSC primarily and evaluative norms secondarily. For example, "a speech community has historically been defined (at least within variationist sociolinguistics) as a group of people who share the same constraints on, and social evaluation of, intraspeaker variation" (Tamminga et al., 2016:307), or "we might define the speech community as a community of individuals who share the same variable grammar (i.e., a system of constraints) and evaluative norms...[or] we might define the speech community independently...but assume that all individuals within it share the same grammar" (Blaxter et al., 2019:92). SCSC has even 
been used as a diagnostic of shared speech community membership, as in Bayley and Villarreal's (2019:212) finding in a small Texas town that "Latinos and Anglos do not form a single speech community with respect to [coronal stop deletion]" due to differences in internal constraints. In short, although SCSC was not originally part of the Labovian framework, by now it is firmly entrenched in variationist theory and practice.

GENDER AND SOCIOLINGUISTIC VARIATION ${ }^{1}$

A large body of research on external factors in sociolinguistic variation has found gender to be among the strongest and most consistently influential external factors on variation (Cheshire, 2004; Labov, 1990, 2001). This wealth of findings from numerous speech communities around the world led Labov (1990, 2001) to formulate general principles of the empirical relationship between gender and language variation and change. These principles all pertain to differences in the rates at which women and men adopt a variable feature; as we discuss below, there has been little inquiry into the degree to which women and men differ in their internal constraints on variables. The principles are:

"Principle I: For stable sociolinguistic variables, women show a lower rate of stigmatized variants and a higher rate of prestige variants than men" (Labov, 2001:266).

"Principle Ia: In linguistic change from above, women adopt prestige forms at a higher rate than men" (Labov, 2001:274).

"Principle II: In linguistic change from below, women use higher frequencies of innovative forms than men do" (Labov, 2001:292).

Labov (2001:262) argued that these principles are so durable and widespread in part because the "pervasive social factors" that delineate gender roles and relations are more deeply embedded in social structure than other means of social grouping and differentiation. James (1996) reviewed explanations that variationists have proposed for the association between women and prestige forms, including exposure to prestige speech, gendered social networks, access to occupational versus symbolic capital, and biological differences in verbal ability. While "the fact that women appear to be universally granted less status and power than men must be recognized as a relevant underlying factor" (1996:119), James concluded that communities will differ as to which factors will play larger roles in producing sociolinguistic gender differences.

Despite the persistent findings of differences in rates of variable usage between female and male speakers, research on sociolinguistic variation has generally assumed that gender (unlike geographical distance or ethnicity) does not divide women and men into separate speech communities. This assumption is implicit in Principle II, in which changes originate with women in a community and diffuse to their male counterparts, and explicit in Labov's account of a pattern found across numerous Philadelphia vowel changes whereby men lag behind 
women by roughly one generation: "men are at the level of linguistic change characteristic of their mothers because they acquired their first use of these variables from their mothers" (Labov, 2001:306-7).

Given this assumption, then, it is not surprising to find a lack of variationist studies contemplating whether women and men may exhibit different internal constraints on variation. In practice, a hypothesis of gender differences in the behavior of the internal constraints operating on a variable would be tested either by presenting different analyses for women and men, or, in a methodological framework which uses statistical modeling, by testing for a statistical interaction between gender and the internal constraints. ${ }^{2}$ (Although only the latter case is an interaction in the strict sense, for convenience we refer to both cases as interactions with gender.) Instead, the preponderant statistical treatment of gender reflects the assumption that women and men differ in rates but not constraints: gender is entered in a statistical model either as a main effect or in an interaction factor with some other external constraint(s) (e.g., a factor that combines gender and class). Our search of the literature yielded few exceptions. First, D'Arcy (2007:396) reported on gender differences in the functions of (be) like among Canadian English speakers: women are more likely to use be like as a quotative, men are more likely to use like as a discourse marker, and both are equally likely to use it as an adverb. It is unclear, however, whether this pattern exemplifies women and men applying different grammatical constraints to the same variable, as arguably quotative be like, discourse particle like, and adverbial like are different sociolinguistic variables that overlap in phonological form. Second, among Dubois and Horvath's (2000:311) youngest generation of Cajun English speakers, women's rates of nasalization and voiceless stop nonaspiration virtually reach zero, whereas men "recycle" these older markers of Cajun English; these are features, in other words, for which young men retain variable grammars and which young women avoid categorically. Finally, several generations of gender-segregated Deaf schooling in Dublin resulted in gendered Irish Sign Language lexicons_-including signs as commonplace as those for girl, work, and use-that persisted after students left school and were sufficiently distinct to impede cross-gender ISL communication (LeMaster, 2006). In short, despite widespread and well-documented differences in rates of variable usage between women's and men's speech, the conventional wisdom that women and men share membership in the speech communities they inhabitand thus women and men share variable grammars of internal constraints on variation-has not typically been examined.

Southland occupies 34,347 square kilometers of land at the southernmost tip of the South Island of New Zealand (Grant, 2015). It is sparsely populated, with 97,467 residents as of the 2018 census. ${ }^{3}$ Roughly half of the population lives in the port city of Invercargill, and a plurality of the population works in agriculture, 
forestry, and fishing. Compared to the rest of New Zealand, Southland experiences a harsh climate, with low temperatures, high winds, and high annual rainfall. These conditions have led to a stereotypical association with rural toughness, as personified in the "Southern man" character created to promote Speight's beer, brewed in nearby Dunedin, Otago (Jackson, Gee, \& Scherer, 2009). ${ }^{4}$ Also prominent in the popular imagination is Southland's rhoticity. Te ara, the official encyclopedia of New Zealand, opens its entry on Southland with "The softly rolled 'r's of Southland's inhabitants hark back to their largely Scottish heritage" (Grant, 2015:n.p.). Southland rhoticity is commonly described as "rolled" even though its phonetic form is $[\mathrm{I}]$ or $\left[3^{\mathrm{c}}\right]$ rather than $[\mathrm{r}] .^{5}$ Although both SldE and General New Zealand English (GNZE) retain "linking R" in prevocalic position (e.g., bee[ $[\ell]$ and wine), rhoticity in nonprevocalic position has been absent from GNZE since around 1900 (Hay \& Sudbury, 2005:806); the present paper focuses exclusively on nonprevocalic rhoticity. Moreover, as indicated by the quotation from Te ara, common wisdom in New Zealand attributes SIdE rhoticity to colonization patterns. Compared to most of New Zealand, in which English settlers predominated, Southland and neighboring Otago had a greater share of Scottish in-migration. In the 1871 census, $61.4 \%$ of Southland's UK-born residents came from Scotland, while the figure in Otago was $51.5 \%$; in no other province did the number of Scots reach more than $21 \%$ of those born in the UK (Philips \& Hearn, 2013:148).

In the only previous large-scale study of SldE, Bartlett (2002) found that rhoticity declined across the twentieth century, only to experience a resurgence in the phonological environment of a preceding NURSE vowel; ${ }^{6}$ this was a change being led by young urban women. However, this analysis did not have the benefit of modern statistical techniques such as mixed-effects regression modeling to account for the differential levels of variation for individual words or speakers (e.g., Baayen, Davidson, \& Bates, 2008). Thus, our aim in this research was to leverage these modern tools to analyze data from Bartlett and additional sources to investigate the trajectory of rhoticity in Southland across the twentieth century. While we did not initially set out to test the null hypothesis that women and men belong to the same speech community, Bartlett's previous finding that rhoticity re-emerged in a restricted phonological environment relative to its original form led us to test interactions between internal and external constraints - contrary to received wisdom in variationist sociolinguistics (as discussed by MacKenzie, 2012:241-53) - in preliminary modeling. Once we began down this path, the differences between women's and men's constraints were impossible to ignore.

METHODS

\section{Data}

Data were drawn from the Southland corpus hosted by the New Zealand Institute of Language, Brain, and Behaviour at the University of Canterbury, New Zealand. 
This corpus consists of over eighty-three hours of mostly spontaneous speech recordings of 113 Southlanders born between 1868-1998. This corpus is hosted in an instance of LaBB-CAT (Fromont \& Hay, 2012), a browser-based linguistics research tool that facilitates the storage and searching of time-aligned corpora of audio and/or video recordings. Of the $10,337 / \mathrm{r} /$ tokens examined in this study, 5,430 came from Bartlett's (2002) corpus of sociolinguistic interviews in Southland, 3,287 from the Southland Oral History Project (made available with the assistance of the Invercargill City Libraries and Archives), 565 from the Intermediate Archive (Gordon, Maclagan, \& Hay, 2007), 541 from QuakeBox (Clark, MacGougan, Hay, \& Walsh, 2016), and 514 from an unpublished corpus of interviews conducted by the third author in Southland. These recordings were originally created for the purposes of sociolinguistic research and/or oral history documentation. All tokens came from stressed syllables in content words and from spontaneous speech, rather than read-speech tasks. We restricted the sample to 101 speakers born between 1900-1985 for whom we had information on where in Southland the speaker had grown up. Speakers' birth years were divided into three 'generations' (1900-1935, 19361955, 1956-1985) based on the distribution of birth years in the data. Speakers were also divided into two regional groups, urban (Invercargill) versus rural, based on where they grew up.

In keeping with well-established variationist practice for English /r/ (e.g., Becker, 2009:645; Blaxter et al., 2019:96; Gordon, Campbell, Hay, Maclagan, Sudbury, \& Trudgill, 2004:93; Labov, Ash, \& Boberg, 2006:47; Nagy \& Irwin, 2010:242), tokens were coded into a Present (i.e., $r$-ful) versus Absent (i.e., $r$-less) binary. In SldE, this distinction subsumes several phonetic processes, depending on lexical set: coda $[\mathrm{I}]$ versus compensatory lengthening (e.g., START [a.I $\sim \mathrm{a}:]$ ), coda $[\mathrm{I}]$ versus a centering offglide (e.g., NEAR [II $\sim \mathrm{I}$ ə]), and r-coloring versus no r-coloring (e.g., NURSE [ $\left.3^{\sim} \sim 3\right]$ ). A minority of tokens were coded by hand by Chris Bartlett, with the remainder automatically coded by a random-forest classifier (Breiman, 2001) run in $\mathrm{R}$ using the packages ranger and caret (Kuhn, 2018; R Core Team, 2019; Wright \& Ziegler, 2017). In brief, this method uses machine learning to predict whether $/ \mathrm{r} /$ tokens are Present or Absent based on the degree to which their acoustic signatures resemble those of tokens known to be Present or Absent. To evaluate the classifier's auto-coding predictions, Villarreal, Clark, Hay, and Watson (2020) conducted an experiment in which eleven phonetically trained listeners provided coding judgments for sixty $/ \mathrm{r}$ / tokens from male speakers; there was a significant relationship between the classifier's auto-codes and listeners' judgments, indicating that classifier's autocodes match up well with humans' perceptions of $/ \mathrm{r} /$. While this method is by no means perfect, the same is true of human coders, with intercoder agreement for $/ \mathrm{r} /$ coding typically ranging from 75-87\% (e.g., Lawson, Scobbie, \& StuartSmith, 2014:66; Fosler-Lussier, Dilley, Tyson, \& Pitt, 2007:935).

Given the importance of gender differences in the present research, we augmented the earlier classifier method to ensure that the classifier predicted tokens from women and men with equal accuracy. In particular, we used two 
strategies from the literature on algorithmic fairness (e.g., Berk, Heidari, Jabbari, Kearns, \& Roth, 2018:27): we ensured equal proportions of Present tokens among women and men in the training set of tokens with known codes (by removing a randomly chosen subset of women's Absent tokens), and we excluded the four acoustic measures pertaining to pitch. ${ }^{7}$ This classifier, run on 176 acoustic measures from 3,723 hand-coded tokens from Bartlett's corpus, achieved satisfactory gender fairness. The overall cross-validation accuracy rates for women and men differed by 0.7 percentage points (women: 82.8\%; men: 83.5\%); among Absent tokens, the difference in accuracy was 2.4pp (women: 92.8\% ; men: 90.4\%), and among Present, 6.8pp (women: 62.9\%; men: 69.7\%). ${ }^{8}$ As a result, we applied this gender-balanced classifier to automatically code several thousand additional / $\mathrm{r} /$ tokens in the Southland corpus; the data set for the present analysis of $/ \mathrm{r} /$ (totaling 10,337 tokens) includes 8,333 auto-coded tokens and 2,004 hand-coded tokens. ${ }^{9}$ Readers can find this data set at https:// github.com/nzilbb/Sld-R-Data.

\section{Modeling}

We performed statistical analysis via mixed-effects logistic regression models in $\mathrm{R}$ using the package lme4 (Bates, Mächler, Bolker, \& Walker, 2015; R Core Team, 2019). As mentioned above, preliminary modeling revealed noticeable differences in constraints on variation between women and men. We attempted to examine this pattern statistically, by testing for interactions between internal and external constraints. However, the models that contained these interactions failed to reach convergence; this is likely due to the different patterns of variation by gender over time, to which we return later. To move forward, we instead fit separate models by gender; we refer to these models as ALL-F $(n=$ 4402) and ALL-M $(n=5908)$. These models revealed greater rhoticity after the NURSE vowel than after other vowels, ${ }^{10}$ suggesting that this phonological context may be the site of sociolinguistic differentiation that would be difficult to detect in the larger models. As a result, we also ran additional models on the subset of tokens after NURSE (women $n=1237$, men $n=1686$ ); we refer to these models as NURSE-F and NURSE-M. Auto-coded tokens comprised $87.3 \%$ of the ALL-F dataset, $75.6 \%$ of ALL-M, $87.5 \%$ of NURSE-F, and $75.0 \%$ of NURSE-M. Details about predictors tested and the model-fitting process can be found in Appendix A.

\section{RES ULTS}

Five predictors emerged as significant in at least one of the four models: Generation, Preceding vowel, Following segment, Word-final, and Region. Table 1 summarizes the predictors contained in each model. (Detailed model summary tables can be found in Appendix B.) The broad commonalities across models were greater rhoticity after NURSE than other vowels (with this split increasing in apparent time) and greater rhoticity among rural than urban speakers. Beyond those commonalities, however, a comparison of women's and 
men's patterns revealed some noticeable differences. In the following subsections, we first discuss the internal factors constraining rhoticity among women and men, then we discuss the effect of Region.

\section{Internal constraints: Women}

Model ALL-F revealed a significant Generation $\times$ Preceding vowel interaction (Figure 1), indicating that women's rhoticity after NURSE increased with each generation, especially from the middle to the younger generation. There is little change in rhoticity after START, NORTH, and Other vowels across generations of women, with very low levels of rhoticity regardless of generation. In this sense, the Generation $\times$ Preceding vowel interaction does not reveal a reorganization of the Preceding vowel constraint among women but rather demonstrates the widening of a pre-existing binary split between more-rhotic NURSE and less-rhotic nOn-NURSE contexts.

ALL-F and NURSE-F revealed a significant main effect of Following segment (Figure 2). In both models, following dorsal and labial obstruents favored rhoticity to a greater extent than coronal obstruents or sonorants; the prepause environment, present only in ALL-F, also favored rhoticity. The similarity of this constraint's effect in both women's models suggests that, despite the split in rhoticity after NURSE versus other contexts, women's Following segment constraint was not mediated by Preceding vowel contexts. In addition, it is worth noting that, unlike both men's models (see below), neither women's model had a significant Generation $\times$ Following segment interaction, indicating that the effect of Following segment was stable across generations.

\section{Internal constraints: Men}

The significant Generation $\times$ Preceding vowel interaction in ALL-M (Figure 3) revealed a complex reorganization of the Preceding vowel constraint for Southland men. In the oldest generation, men exhibit a three-way split, with greatest rhoticity after NURSE, middling rhoticity after START and Other, and little rhoticity after NORTH. In the middle generation, rhoticity increases after NURSE to near-categorical levels and drops in all other contexts (becoming rare after NORTH). This shift to a two-way split is cemented in the youngest generation; rhoticity remains at high levels after NURSE (despite a small decline from the middle generation), and rhoticity is rare after START, NORTH, and Other.

Two other internal constraints are likewise in flux across generations of men in ALL-M, with significant Generation $\times$ Following segment $\times$ Region and Generation $\times$ Word-final interactions. The latter interaction exhibits the unusual pattern wherein Word-final briefly becomes more influential in the middle generation before considerably decreasing in strength again in the youngest generation (Figure 4).

The different ways that these three internal constraints play out across apparent time suggests instability in Southland men's constraint grammars of rhoticity. Indeed, this observation is borne out in a cross-Generation comparison of 
TABLE 1. Summary of significant predictors of / $/$ / presence, levels and token numbers within each level for models

\begin{tabular}{|c|c|c|}
\hline Model & Predictor & Levels (num. obs.) \\
\hline \multirow{5}{*}{$\begin{array}{l}\text { ALL-F } \\
(n=4402, \\
18.0 \% \text { Present })\end{array}$} & Generation & 1900-1935 (1925), 1936-1955 (1256), 1956-1985 (1229) \\
\hline & Preceding vowel & START (913), NORTH (1440), NURSE (1237), Other (820) \\
\hline & Region & Invercargill (1837), RuralSld (2573) \\
\hline & $\begin{array}{l}\text { Following } \\
\text { segment }\end{array}$ & $\begin{array}{l}\text { LabialObs (205), CoronalObs (2437), DorsalObs (538), } \\
\text { Sonorant (967), Pause (263) }\end{array}$ \\
\hline & (Interactions) & Generation $\times$ Preceding vowel, Preceding vowel $\times$ Region \\
\hline \multirow{6}{*}{$\begin{array}{l}\text { ALL-M } \\
(n=5908, \\
37.7 \% \text { Present })\end{array}$} & Generation & 1900-1935 (3802), 1936-1955 (1517), 1956-1985 (607) \\
\hline & Preceding vowel & START (1396), NORTH (1775), NURSE (1689), Other (1066) \\
\hline & $\begin{array}{l}\text { Following } \\
\text { segment }\end{array}$ & $\begin{array}{l}\text { LabialObs (373), CoronalObs (3329), DorsalObs (712), } \\
\quad \text { Sonorant (1261), Pause (251) }\end{array}$ \\
\hline & Region & Invercargill (2371), RuralSld (3555) \\
\hline & Word-final & FALSE (5179), TRUE (747) \\
\hline & (Interactions) & $\begin{array}{l}\text { Generation } \times \text { Preceding vowel, Preceding vowel } \times \text { Region, } \\
\text { Generation } \times \text { Word-final, Generation } \times \text { Following } \\
\text { segment } \times \text { Region }\end{array}$ \\
\hline \multirow{3}{*}{$\begin{array}{l}\text { NURSE-F } \\
(n=1237 \\
47.0 \% \text { Present })\end{array}$} & Generation & $1900-1935$ (555), 1936-1955 (341), 1956-1985 (341) \\
\hline & $\begin{array}{l}\text { Following } \\
\text { segment }\end{array}$ & $\begin{array}{l}\text { LabialObs (44), CoronalObs (471), DorsalObs (309), Sonorant } \\
\quad \text { (413) }\end{array}$ \\
\hline & Region & Invercargill (557), RuralSld (680) \\
\hline \multirow{4}{*}{$\begin{array}{l}\text { NURSE-M } \\
(n=1686, \\
69.5 \% \text { Present })\end{array}$} & $\begin{array}{l}\text { Following } \\
\text { segment }\end{array}$ & $\begin{array}{l}\text { LabialObs (92), CoronalObs (651), DorsalObs (454), Sonorant } \\
\quad(492)\end{array}$ \\
\hline & Generation & 1900-1935 (1053), 1936-1955 (453), 1956-1985 (183) \\
\hline & Region & Invercargill (809), RuralSld (880) \\
\hline & (Interactions) & Region $\times$ Following segment, Generation $\times$ Following segment \\
\hline
\end{tabular}

constraint strength for Following segment, Preceding vowel, and Word-final in ALLM. Whereas Following segment and Word-final become less influential in men's constraint grammars, the Preceding vowel constraint becomes stronger (Table 2). The middle generation can thus be interpreted as a period of competition between constraints, after which men settled on a grammar in which-as with women across generations - the influence of Preceding vowel overshadowed other internal constraints.

Among men's /r/ after nurse, Following segment also experiences change across time and space. The significant Generation $\times$ Following segment interaction in NURSE-M indicates that the retreat among the youngest generation in rhoticity after NURSE is led by tokens with following sonorants (Figure 5). The arrangement of Following segment constraint levels among men (dorsal obstruents favor rhoticity to a greater degree than sonorants or labial/coronal obstruents) differs from women's (Figure 2, right panel), notably in the effect of labial obstruents. In addition, a significant Region $\times$ Following segment interaction in NURSE-M suggests an urban/rural split in the effect of following coronal obstruents, with rural men significantly more rhotic in this environment than urban men. 


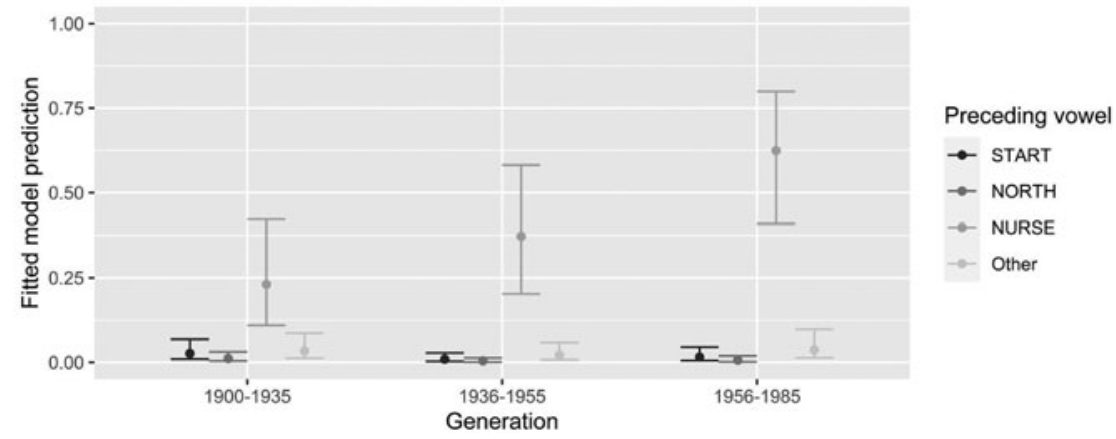

FIGURE 1. Model ALL-F $(n=4402)$ Generation $\times$ Preceding vowel interaction (dots indicate fitted means and bars indicate limits of $95 \%$ confidence intervals).

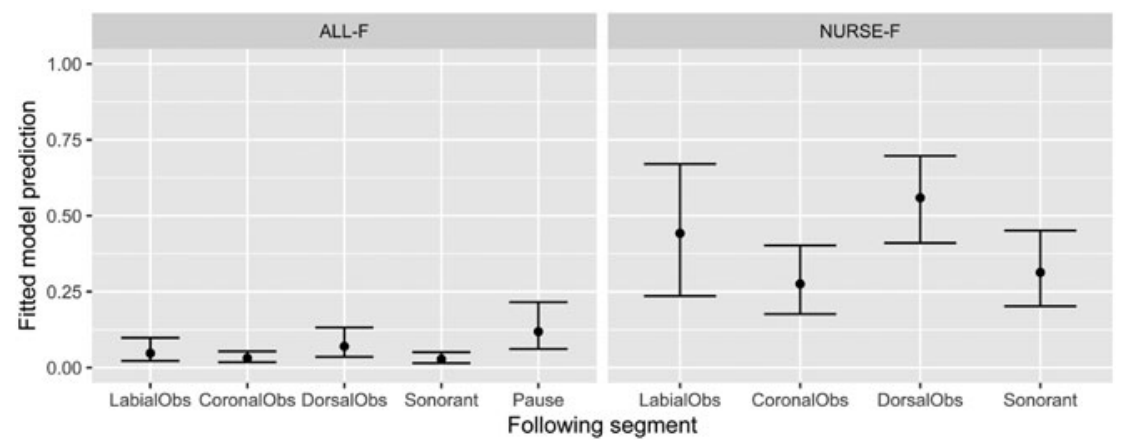

FIGURE 2. Models ALL-F $(n=4402)$ (left) \& NURSE-F $(n=1237)$ (right) Following segment main effect (note that NURSE-F excluded following pauses).

\section{Interim summary: Internal constraints}

While both women's and men's models indicate greater rhoticity after NURSE than after other vowels, and both indicate this NURSE/non-NURSE split increasing in apparent time, the similarities between women and men largely stop there. ${ }^{11}$ First, whereas women already have a two-way (NURSE/non-NURSE) Preceding vowel split in the oldest generation and then increase the size of this split, men in the oldest generation have a three-way Preceding vowel split that gradually becomes a two-way split resembling the women's pattern. Second, whereas the oldest men were already much more rhotic than women after NURSE (71.0\% versus $23.1 \%$ ) and quickly increased to become near-categorically rhotic in this environment, women increased their rhoticity after NURSE only gradually. Third, whereas women's Following segment constraint is stable across generations and regions, men's Following segment constraint changes across generations and regions. Finally, men's internal constraints undergo a period of competition in the middle generation before settling on a constraint hierarchy similar to the women's. 


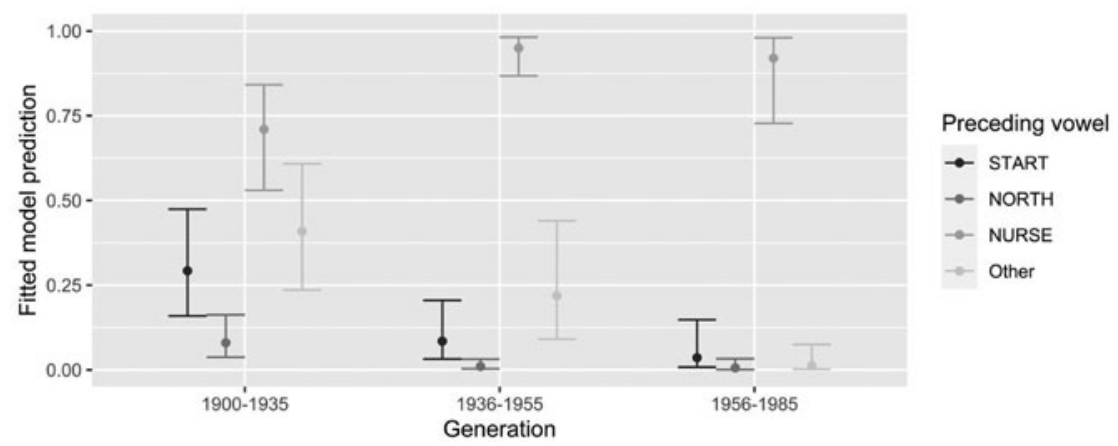

FIGURE 3. ALL-M $(n=5908)$ Generation $\times$ Preceding vowel interaction.

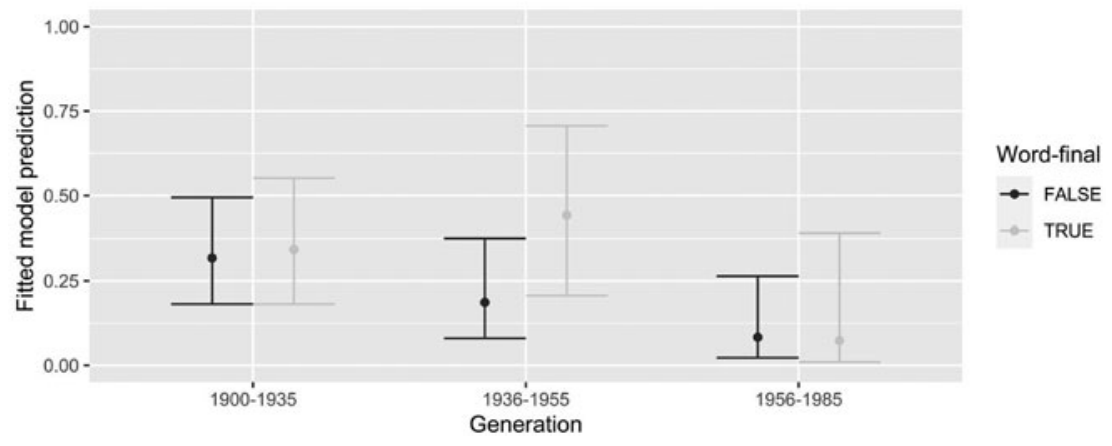

FIGURE 4. Model ALL-M $(n=5908)$ Generation $\times$ Word-final interaction.

In other words, the differences between women's and men's constraint grammars cast doubt on the assumption that women and men-nominally members of the same speech community - shared a community grammar. (This is especially true of the oldest generation, though there remain vestigial differences, such as Following segment with NURSE, even among the youngest speakers.) This observation contradicts long-established findings about the way gender affects sociolinguistic variation. In the Discussion, we revisit this contradiction in light of the sociohistorical context of gender in twentieth century Southland.

\section{Region}

Beyond internal factors, all models included Region as significant, as rural speakers were more rhotic than speakers from the urban area of Invercargill. Region significantly interacted with Preceding vowel among both women and men; among men, the urban/rural split was present across all Preceding vowel environments, while among women, the urban/rural split was limited to preceding NURSE and Other (Figure 6). Although ALL-F did not support an 
TABLE 2. Factor ranges by Generation for three internal constraints in model ALL-M (difference in fitted means between levels that most and least favor rhoticity, excluding Pause for Following segment)

\begin{tabular}{cccc}
\hline \hline Generation & Following segment & Preceding vowel & Word-final \\
\hline $1900-1935$ & 0.305 & 0.630 & 0.025 \\
$1936-1955$ & 0.265 & 0.939 & 0.256 \\
$1956-1985$ & 0.229 & 0.914 & 0.01 \\
\hline \hline
\end{tabular}

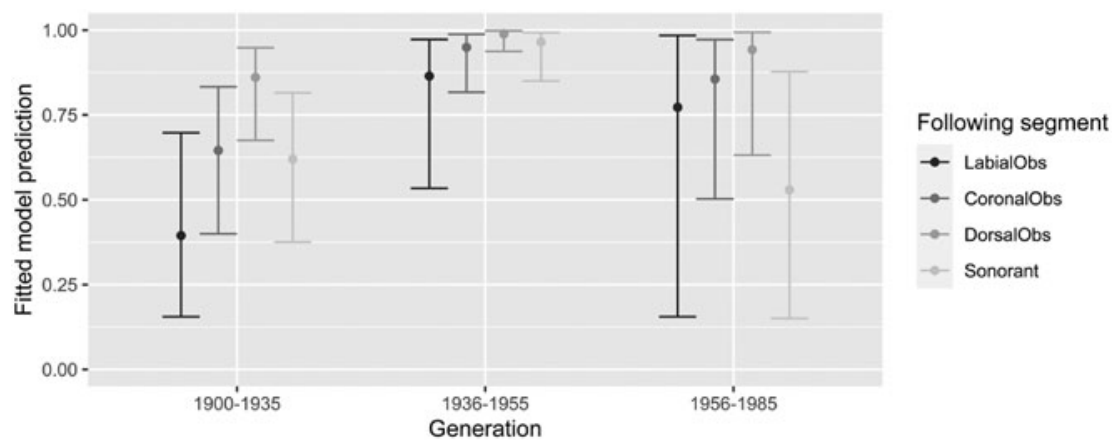

FIGURE 5. Model NURSE-M $(n=1686)$ Generation $\times$ Following segment interaction.

intergenerational comparison of this interaction, this pattern suggests that, among women, rural speakers are leading the change toward greater rhoticity after NURSE.

Unlike for women, the effect of Region was also mediated by Generation and Following segment for men. The Generation $\times$ Following segment $\times$ Region interaction in ALL-M indicated that the urban/rural split shrank over the twentieth century and that this change proceeded unevenly across Following segment environments. In addition, as mentioned above, after NURSE rural men are significantly more rhotic with following coronal obstruents than urban men. As with their female counterparts, among men rural speakers are more rhotic than urban speakers, and rural men (especially in the oldest generation) are the most rhotic group in Southland. In this respect, the sociolinguistic facts accord with the popular stereotype of the "Southern man": rural and rhotic.

\section{DIS C US SION}

Our results show that women and men in early twentieth century Southland had different constraint grammars operating on their variable use of rhoticity. If we follow the argumentation of SCSC, then the logical conclusion is that women and men formed different speech communities for at least some of the time in the early twentieth century in Southland. How can this be possible in a society 
where women and men live together, raise children together, and interact with one another? In an effort to understand our data, we investigated descriptions of gender practices in the literature on social history in New Zealand between 1840 and $1980 .{ }^{12}$ One study in particular provided us with a very detailed account of the typical relationship between gender and social practice in Southland, New Zealand. Lovelock (1993) is an ethnography of a small industrial town in Eastern Southland called Mataura. It was selected as a research site because the two main industries of the town (the Freezing Works and the Paper Mill) have been in operation since the late 1800s and they represent "a microcosmic illustration" of New Zealand's two main employment types at the time of the study: manufacturing and meat processing. Thus, although Lovelock (1993) describes the life and work habits of only one small town in Southland, it is arguably representative of other small settlements in New Zealand (especially in the South Island). Lovelock spent a year in the late 1980s living and working in this community, interviewing two hundred residents (from a population of $2,000)$, teaching at the local high school, socializing in the community, and compiling a thoroughly detailed and lengthy ethnographic account of life, gender, and work. This work provides compelling evidence of myriad ways in which girls and boys, women and men occupied different social spaces for much of their time; our findings of different constraint grammars for women and men are actually not surprising in light of this persistent gendered social separation.

Lovelock described how this gendered "segregation"13 begins at an early age, continues throughout the lifespan and was (until recently) also sanctioned by the state. Public policy ensured that, for the most part, married women would not be part of the workforce, and they would remain in unpaid domestic labor through a series of gendered wage-fixing policies and the denial of access to welfare. From 1894, the New Zealand government instituted a male breadwinner wage which was promoted as a "family wage" in 1935. This meant that employers were bound to pay men enough to support the man himself, his wife, and two children.

The families interviewed by Lovelock in the late 1980s describe how their children begin to take on responsibility for certain household tasks at around the age of five or six, and this continues on into adolescence. This work is very clearly gendered: "girls help their mothers with baking and cleaning around the house. Boys help their fathers with outside jobs, such as lawn mowing, putting the rubbish out, collecting the firewood and coal, and 'cleaning up' in the garage" (Lovelock, 1993:105). This means that, from an early age, not only are there certain jobs that are determined suitable for females and males in the household, but girls and boys are encouraged to spend time with their samegendered parent, occupying a different part of the household space (girls are inside, boys are outside) from their other gendered siblings.

Children enter the school system in New Zealand at age five. In a small number of single-gender schools, children are exposed only to their same-gender peers throughout their school years. But even in co-educational schools, there are clear ways in which girls and boys demarcate their social spaces and remain 


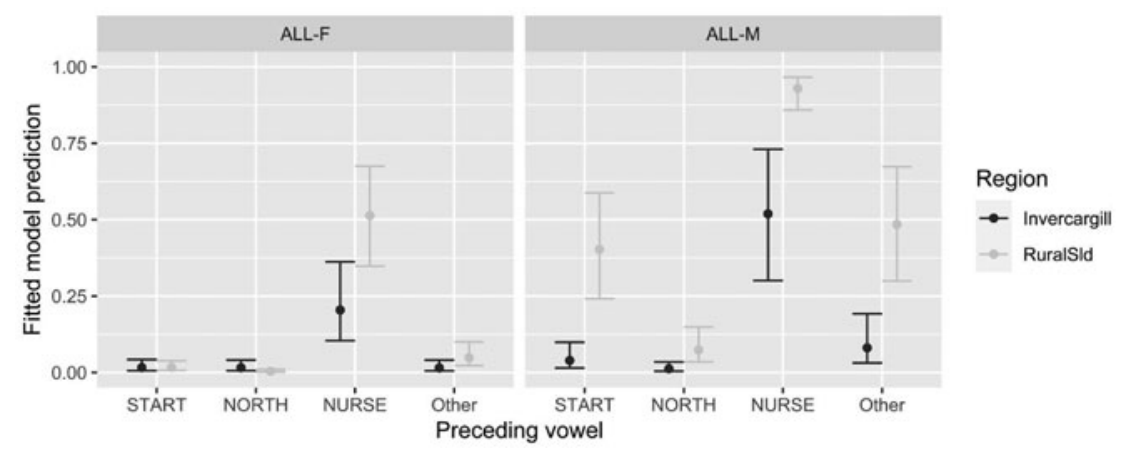

Figure 6. Models ALL-F $(n=4402)$ (left) \& ALL-M $(n=5908)$ (right) Preceding vowel $\times$ Region interaction.

somewhat separate. Lovelock taught at the local high school in Gore (the school serving Mataura students) and describes her experiences of witnessing this gendered social separation first-hand. In mixed-gender core subjects, desks were organized in rows of twos, and students always sat with their same-gender friends. In the optional school subjects, Lovelock describes a very clear gender divide "...with adolescent girls being more likely to take typing, shorthand, home economics, and the adolescent boys being more likely to take woodwork, metal work, technical drawing" (1993:114).

Even clearer evidence of the social separation between women and men is found in gender practices in the workforce (the main focus of Lovelock's research). Firstly, the "man as breadwinner" model that had existed for generations in New Zealand and elsewhere was still held up as the ideal, even though, in the changing economic climate of the late 1980s, this model was no longer practical or attainable. Men were expected to hold full-time employment, and this should continue once they were married and had a family. Women should attain paid employment until they were married, but they were expected to leave the workplace soon after, in order to become full-time home makers and mothers. The average school-leaving age was sixteen, and the average age for a female to be married was twenty-one. This means that it was common for same-aged women and men to share the same place of work for around five years before the women left the workforce for a life of unpaid domestic responsibilities. Rarely did these women return to the paid workforce; even if work was available (often not the case in Mataura), women were on average fifty-four years old when their last child left school (Koopman Boyden \& Scott, 1984).

Even when women and men worked for the same employer, they were often separated by task and space. For instance, when the Freezing Works in Mataura began to employ women in the 1960s for the first time-it opened in the late 1880 s - women worked in packaging, a task for which the management of the Freezing Works believed that women could "put their more dexterous fingers to work" (Lind, 1981, cited in Lovelock, 1993:252). This packaging process also 
took part in a separate part of the factory away from the slaughter board, and so "women were also allocated separate space... and laboured alongside one another rather than the men" (Lovelock, 1993:252). The workforce was similarly gendersegregated in the Paper Mill with men working inside the mill making paper and women working in an adjacent building assembling paper bags. Even during World War II, when women were entering the workforce in greater numbers, the main employers in Mataura maintained a gender-separated workforce by transporting men from nearby areas to fill the "men's jobs" while women were employed locally in a small munitions factory. According to Lovelock (1993:245) "once the war was over the women returned to their homes- the gendered composition of local established industries remaining throughout the war and after, virtually unchanged."

Beyond the working world, Lovelock described not only how the introduction of the forty-hour work week in 1936 introduced the new concept of leisure time to New Zealanders, but how this leisure time was also gendered, with the establishment of working mens' clubs, sports teams, and the Young Farmers club for men, while women were directed towards the Country Women's Institute or The Plunket Society. This gender separation in social life persisted in 1980s Mataura. At various points in the discussion, Lovelock described attending social gatherings with her male partner but spending little time together because women and men were separated by social and physical space: "the women were in the kitchen seated around the kitchen table, the men were in the lounge standing in a semi-circle" (Lovelock, 1993:64). Even when couples (married women and men) did inhabit the same physical space as each other, the majority of participants described their communication as relatively pragmatic; they would talk about their children or what they would be doing on the weekend. The women in the study often stated that if they had "worries" or wanted to communicate their emotions more explicitly, they would more likely do this with female friends or female family members. Taken together, the picture that emerges from one Southland small town is one in which girls and boys, women and men are encouraged, from a very young age, to separate themselves from the other gender even while still co-existing in the same physical space, often even in the same family unit.

\section{Gender separation beyond Southland}

The story of gender practices we are reporting here is not unique to Mataura, or Southland more generally. In many ways, the gender practices that are reported in Southland (and elsewhere in New Zealand, see James [1985]) mirror gender practices already well established in Britain in the eighteenth and nineteenth century. As Philips and Hearn (2013:12-3) explained, most of the 500,000 British immigrants who settled in New Zealand from 1840 to the early 1900s brought with them "a host of habits and ways of living - patterns of speech, a taste for certain foods and drinks, religious practices, ways of relating to family and friends, forms of leisure and recreation, and different styles of expressing 
feelings from humor through to stoicism and even anger." Philips and Hearn argued that these practices persisted into New Zealand society: "such cultural practices were not stripped off the moment the migrant got on the boat. They were carried to the New World where they helped determine the way the newcomer faced a different environment and a new mix of neighbours and institutions." Lovelock (1993) echoed this argument in her discussion of immigrants arriving and settling in Southland in particular. She suggested, based on various primary sources (newspapers, diaries, and oral histories from early settlers of the Southland region), that the division of labor among women and men in the 1800 s and early 1900s in Southland "did not contravene what they had been socialised to do 'back home' [i.e., in Britain]" (1993:207-8).

Indeed, seminal work on gender roles in social history has found that American society was similarly characterized by rigid gender differentiation between the mideighteenth to nineteenth centuries (Smith-Rosenberg, 1975). Smith-Rosenberg (1975) analyzed a corpus of correspondence and diary entries from thirty-five American families between 1760 and 1880. A compelling picture emerges from this research in which women (kin and friends) were bound together in both physical and emotional intimacy throughout their lives, and a specifically female support system existed, which was "institutionalized in social conventions or rituals which accompanied virtually every important event in a woman's life, from birth to death" (Smith-Rosenberg, 1975:9). At the same time, "severe social restrictions" (1975:9) were placed on communication and especially intimacy between young women and men. Of course, much like in Mataura in the late 1980s, the young women described by Smith-Rosenberg (1975) sought marriage and a life of domesticity, but even married life remained structured around same-gendered activities. Childbirth, for instance, involved a lengthy seclusion from the husband before and after delivery, which was supervised by mothers, sisters, and female friends. Miscarriages and deaths, like births, were similarly structured around elaborate gender-segregated rituals. Given this extreme separation of women's and men's interaction and social worlds, we should not be surprised to find variables in these communities that patterned akin to $/ \mathrm{r} /$ in early twentieth century Southland, with differences in women's and men's constraints on variation.

\section{Convergence in the youngest generation of Southlanders}

Our investigation into gender practices in early Southland (and elsewhere) suggests that it is at least possible, even highly likely, that women and men had different constraints on rhoticity in the first half of the twentieth century, because they quite literally inhabited different (speech) communities. But our analysis also shows that women and men born in the second half of the twentieth century eventually converged on a similar (though not identical) constraint grammar. So, what changed in Southland to facilitate the emergence of a shared, nongenderdifferentiated community grammar? Although Southland experienced changes in the structure of work practices (which led to changes in social attitudes 
elsewhere in New Zealand), we hypothesize that changes in economic circumstances brought about greater contact between women and men, which in turn promoted linguistic convergence.

We mentioned above that gender separation was sanctioned by the state, with, for example, the male breadwinner wage that was introduced in 1935. This was not removed from law until private sector equal pay legislation was introduced (1972) and antidiscrimination legislation such as the Human Rights Commission Act (1977) and the Maternity Leave and Employment Protection Act (1980). This was an important step in assisting women into the workforce in greater numbers. The timing of this shift in public policy coincided with changes in social attitudes. In New Zealand, from the 1960s to the 1980s, the women's liberation movement played an important role in consciousness raising and establishing social change in the major urban centers (Dann, 2015). And yet, from the discussions presented in Lovelock (1993), it is unclear whether women in late-1980s Mataura felt the impact of these changes in public policy or changes in attitudes. Lovelock reported that, in Mataura, 90\% of all participants felt that married women with children should not work in paid employment, as those that did were not only neglecting their children and husbands, but were also "taking jobs away from single people and married men" (Lovelock, 1993:357). The women of Mataura almost unanimously agreed that it was "natural" to want to marry, have children, and work in the home. In other words, there is no evidence that women and men in the youngest generation in our data would have developed a markedly different worldview from those speakers in the oldest and middle generations. Changes in attitudes and changes in public policy are unlikely to be the sole reasons for convergence of the constraints in our data.

A more likely account, in our view, is that the economic recessions in the 1960s and 1980s were important contributors to breaking down gender norms. New Zealand went from almost zero unemployment in the early 1960 s to a recession in 1967 caused by a collapse in the wool market. The period between 1984 and 1988 was a time of enormous social and political change in New Zealand. A new Labour government won a landslide victory and promptly removed almost all agricultural subsidies. The immediate effect of this policy for many rural communities, including Southland, was devastating, as nationwide unemployment rose to an all-time high of $11.2 \% .{ }^{14}$ Our working hypothesis is that while attitudes about the roles of women and men in society may have remained largely unchanged in Southland in the youngest generation, in practice, men were increasingly likely to be either unemployed, or employed part-time or in seasonal work during the 1980s and 1990s. In terms of the timeline of our data, this means that, in the youngest generation, men were far more likely to have spent more time in the home than in the oldest and middle generations. In other words, what may have set the youngest generation apart is a loosening of the strict spatial separation between home and work that Lovelock described in Mataura. Based on the available evidence, we hypothesize that the emergence of a nongender-differentiated community grammar, or set of shared constraints operating on nonprevocalic $/ \mathrm{r} /$ in Southland, was driven by economic and social 
factors that culminated in an increased frequency of contact between women and men.

CONCLUSION

Our initial aim in this research was dialectological-we wanted to implement modern methods of statistical analysis in order to better understand the trajectory of phonological change that had reportedly taken place with respect to rhoticity in Southland English. However, in doing this, we discovered, to our surprise, that the internal constraints operating on nonprevocalic $/ r /$ in early twentieth century Southland were different for women and men. If we assume the Speech Community as Shared Constraints Hypothesis, whereby the existence of a community grammar defines and delimits speech communities, Southland women and men effectively constituted different speech communities in the early twentieth century. Despite a large body of variationist research on language and gender, with well-documented differences in rates of variable usage between women's and men's speech, to our knowledge this phenomenon of different gendered speech communities is nearly unattested.

These results can be explained as a product of a particular set of sociohistorical facts about Southland: girls and boys were socialized into same-gender social practices in the home from an early age, gender separation was continued informally in school and then enforced more rigidly in the workplace, and also legitimized by the state. But many of these circumstances are not peculiar to Southland, nor to rural New Zealand. Prominent scholars of social history have been arguing for years that western societies were historically characterized by rigid gender-role differentiation. We suspect that interactions between gender and internal constraints are therefore likely to be found elsewhere; we have not found these interactions in sociolinguistic work before now because we simply have not looked for them. If we are right - if further research does indeed reveal interactions of gender and internal constraints in contexts beyond Southlandthis will suggest that there may be more ways in which multiple speech communities can co-exist in the same geographical area.

SUPPLEMENTARY MATERIAL

To view supplementary material for this article, please visit https://doi.org/10. $1017 /$ S0954394521000090

\section{AC K N O W LED G MEN TS}

This research was made possible by a Royal Society of New Zealand Marsden Research Grant (16-UOC-058). The authors would like to thank members of the New Zealand Institute of Language, Brain and Behaviour for their feedback and support, particularly Jacq Jones for their help with framing language and gender 
research. Thanks are also due to Chris Bartlett and the Southland Oral History Project and Invercargill City Libraries and Archives for sharing data, as well as audiences at the New Zealand Linguistic Society conference, the Australian National University, and the University of California, Davis. Prof Katie Pickles (History Department, University of Canterbury) and UC subject librarians Kerry Gilmour and Dave Clemens were invaluable in finding information on the social history of Southland. Any errors are ours entirely.

\section{NOTES}

1. Although our discussion of gender in this paper revolves around the difference between women and men, we do not mean to deny or erase sexes and genders other than female and male. However, as a majority of research on language and gender deals within this binary, and as the data that we have available only categorizes speakers as women or men, we do not discuss minority genders here.

2. In a related but distinct approach, Labov (1990, 2001:294-319) reported separate models of women and men's production of Philadelphia vowels in order to assess how vowel changes diffuse through the social structure - in other words, this approach assesses the interaction of gender with an external constraint (occupation as a proxy for social class), not internal constraints.

3. Data in this section from New Zealand censuses between 1921-1981 (inclusive) was obtained via hard copy, as this data was not available online as of November 2019; otherwise, data in this section is from Statistics New Zealand (www.stats.govt.nz).

4. The "Southern man" character does not represent Southland to the exclusion of rural parts of the neighboring Otago region but combines the two. Historically, the two regions were settled under similar circumstances, with heavy Scottish in-migration, and indeed Southland was part of Otago until 1861, when it formally became a separate province. Although the rhoticity isogloss has not been systematically investigated, it is clearly not coterminous with the Southland-Otago boundary; our corpus has examples of rhotic twentieth century speakers in Otago locales such as Milton that are nearby to Southland. Nevertheless, since we are less interested in delimiting regional variation in rhoticity than in investigating the development of the SldE speech community, we restrict our sample to speakers from Southland itself.

5. A recent video (https://teara.govt.nz/en/video/20079/a-rolling-r, 0:45) shows a young Southlander reading off a word list, [ $\left.\mathrm{g}^{2} \mathrm{~b}^{2} \mathrm{~d} \mathrm{n}^{\mathrm{c}} \mathrm{S} \mathrm{w}^{2} \mathrm{k}\right]$, and the video presenter responding, "yeah, you do roll your Rs, eh?"

6. In Wells' (1982:xviii-xix) notation for vocalic lexical sets, NURSE stands in for the vowel canonically characterized by the sounds /3:/ in Received Pronunciation and / $3 r /$ in General American English. All vowel environments in this study are referred to using Wells' notation.

7. The tuning parameters for this new classifier were 1,000 trees, fifteen variables tested at each node, Gini splitting rule, minimum node size ten, repeated $k$-fold cross-validation with fourteen folds and three repeats, and SMOTE additional resampling.

8. Thanks to an anonymous reviewer for suggesting the need to look at gender fairness in this classifier.

9. The hand-coded tokens in the analysis of $/ \mathrm{r} /$ reported here constituted a minority of the data on which the classifier was trained. The remaining tokens in the classifier training set did not meet the exclusion criteria mentioned above (stressed syllables, content words, spontaneous speech tasks).

10. The pattern wherein NURSE highly promotes the Present variant (sometimes to the point of being categorical) is common across variably rhotic varieties (e.g., Becker, 2009:646; Labov, 2006/1966:241-4; Nagy \& Irwin, 2010:257).

11. An anonymous reviewer asks whether these differences are "driven by words that are more prevalent in the speech of men versus women in your corpus, or words that are emblematic for men or women." In short, there is some evidence that the differences among tokens after Other vowels may have been driven by lexical effects, but limited evidence for the majority of words. We considered the 160 words that appeared in the combined ALL-F/ALL-M data at a rate of at least one per 1000; these 160 words represented about $80 \%$ of the data. We then calculated Spearman correlations between the normalized rate at which women and men used these words in the data, separately for each Preceding vowel group, in R. These correlations were significant for START, NORTH, and NURSE $(p s<.05)$ but not Other $(\mathrm{S}=3338, \rho=.1778, p=.356)$; among the potentially "emblematic" Other words are engineer ( $n=13,4$ times more likely for men), gear ( $n=19,4$ times more likely for men), care $(n=20,4$ times more likely for women), and wear $(n=20,12$ times more likely for women). 
12. We thank Prof Katie Pickles (History Department, University of Canterbury) and UC subject librarians Kerry Gilmour and Dave Clemens for help with this search.

13. James (1985) is a similar ethnography of life, gender, and work in Kawerau, a town in the Bay of Plenty in New Zealand. The picture that is painted there is a similar one of gender separation: "A central issue is the way in which there is a clear delineation, mentally and actually, of activities into a public 'man's world' and a private 'woman's world'" (32).

14. These figures come from the 2009 Department of Labour publication "How Bad is the Current Recession" (https://web.archive.org/web/20141215020411/http://www.dol.govt.nz/publications/ discussion-papers/current-recession/desc-1.asp).

\section{REFERENCES}

Baayen, R. Harald, Davidson, Douglas J., \& Bates, Douglas M. (2008). Mixed-effects modeling with crossed random effects for subjects and items. Journal of Memory and Language 59:390-412.

Bartlett, Christopher. (2002). The Southland Variety of New Zealand English: Postvocalic / r/ and the BATH vowel. Unpublished $\mathrm{PhD}$ thesis, University of Otago.

Bates, Douglas, Mächler, Martin, Bolker, Ben, \& Walker, Steve. (2015). Fitting linear mixed-effects models using lme4. Journal of Statistical Software 67:48.

Bayley, Robert, \& Villarreal, Dan. (2019). Coronal stop deletion in a rural South Texas community. In E. R. Thomas (Ed.), Mexican American English: Substrate influence and the birth of an ethnolect. Cambridge: Cambridge University Press. 198-214.

Becker, Kara. (2009). /r/ and the construction of place identity on New York City's Lower East Side. Journal of Sociolinguistics 13:634-658.

Berk, Richard, Heidari, Hoda, Jabbari, Shahin, Kearns, Michael, \& Roth, Aaron. (2018). Fairness in criminal justice risk assessments: The state of the art. Sociological Methods \& Research:1-42.

Blaxter, Tam, Beeching, Kate, Coates, Richard, Murphy, James, \& Robinson, Emily. (2019). Each p[ə⿱一土] son does it th[ع:] way: Rhoticity variation and the community grammar. Language Variation and Change 31:91-117.

Breiman, Leo. (2001). Random forests. Machine learning 45:5-32.

Cedergren, Henrietta J., \& Sankoff, David. (1974). Variable rules: Performance as a statistical reflection of competence. Language 50:333-355.

Cheshire, Jenny. (2004). Sex and gender in variationist research. In J. K. Chambers, P. Trudgill, \& N. Schilling-Estes (Eds.), The handbook of language variation and change. Wiley. 423-443.

Clark, Lynn, MacGougan, Helen, Hay, Jennifer, \& Walsh, Liam. (2016). "Kia ora. This is my earthquake story". Multiple applications of a sociolinguistic corpus. Ampersand 3:13-20.

Clark, Lynn, \& Watson, Kevin. (2016). Phonological leveling, diffusion, and divergence: / $/$ lenition in Liverpool and its hinterland. Language Variation and Change 28:31-62.

Dann, C. (2015). Up from under: women and liberation in New Zealand, 1970-1985. Bridget Williams Books.

D’Arcy, Alexandra. (2007). Like and language ideology: Disentangling fact from fiction. American Speech 82:386-419.

Dubois, Sylvie, \& Horvath, Barbara. (2000). When the music changes, you change too: Gender and language change in Cajun English. Language Variation and Change 11:287-313.

Forrest, Jon. (2015). Community rules and speaker behavior: Individual adherence to group constraints on (ING). Language Variation and Change 27:377-406.

Fosler-Lussier, Eric, Dilley, Laura, Tyson, Na'im R., \& Pitt, Mark A. (2007). The Buckeye Corpus of Speech: Updates and enhancements. Paper presented to Interspeech 8, Antwerp, 2007.

Fromont, Robert, \& Hay, Jennifer. (2012). LaBB-CAT: An annotation store. Proceedings of Australasian Language Technology Association Workshop:113-117.

Gordon, Elizabeth, Campbell, Lyle, Hay, Jennifer, Maclagan, Margaret, Sudbury, Andrea, \& Trudgill, Peter. (2004). New Zealand English: Its origins and evolution. Cambridge: Cambridge University Press.

Gordon, Elizabeth, Maclagan, Margaret, \& Hay, Jennifer. (2007). The ONZE corpus. In J. C. Beal, K. P. Corrigan, \& H. L. Moisl (Eds.), Creating and digitizing language corpora: Volume 2: Diachronic Databases. London: Palgrave Macmillan UK. 82-104.

Grant, David. (2015). Southland region. In Te ara: The encyclopedia of New Zealand. Online: https:// teara.govt.nz/en/southland-region.

Guy, Gregory R. (1980). Variation in the group and in the individual: The case of final stop deletion. In W. Labov (Ed.), Locating language in time and space. New York. 1-36.

Hay, Jennifer, \& Sudbury, Andrea. (2005). How rhoticity became /r/-sandhi. Language 81:799-823. 
Jackson, Steven J., Gee, Sarah, \& Scherer, Jay. (2009). Producing and consuming masculinity: New Zealand's (Speight's) "Southern Man". In L. Wenner \& S. Jackson (Eds.), Sport, beer, and gender: Promotional culture and contemporary social life. Zurich: Peter Lang. 181-201.

James, Bev. (1985). Mill Wives: A Study of Gender Relations, Family and Work in a Single Industry Town. Doctoral thesis, Waikato University.

James, Deborah. (1996). Women, men, and prestige speech forms: A critical review. In V. L. Bergvall, J. M. Bing, \& A. F. Freed (Eds.), Rethinking language and gender research: Theory and practice. New York: Addison Wesley Longman. 98-125.

Koopman-Boyden, Peggy Gwendoline, \& Scott, Claudia Devita (1984). The family and government policy in New Zealand. Allen \& Unwin.

Kuhn, Max. (2018). caret $[R$ package], vers. 6.0-81. Online: https://CRAN.R-project. org $/$ package $=$ caret

Labov, William. (1990). The intersection of sex and social class in the course of linguistic change. Language Variation and Change 2:205-254.

(1994). Principles of linguistic change, vol 1: Internal factors. Malden, MA: Blackwell.

(2001). Principles of linguistic change, vol. 2: Social factors. Malden, MA: Blackwell.

(2006/1966). The social stratification of English in New York City, 2nd edition. Cambridge:

Cambridge University Press.

(2007). Transmission and diffusion. Language 83:344-387.

Labov, William, Ash, Sharon, \& Boberg, Charles. (2006). The atlas of North American English: Phonetics, phonology and sound change. Berlin: Mouton de Gruyter.

Lawson, Eleanor, Scobbie, James, \& Stuart-Smith, Jane. (2014). A socio-articulatory study of Scottish rhoticity. In R. Lawson (Ed.), Sociolinguistics in Scotland. London: Palgrave Macmillan. 53-78.

LeMaster, Barbara. (2006). Language contraction, revitalization, and Irish women. Journal of Linguistic Anthropology 16:211-228.

Lind, Clive A. (1981). The Keys to Prosperity: The Centennial History of Southland Frozen Meat Limited. Southland Frozen Meat Limited.

Lovelock, Kirsten (1993). "Reddish eddying waters": a study of work, gender and class consciousness in a working class town. Doctoral thesis, University of Otago.

MacKenzie, Laurel. (2012). Locating variation above the phonology. $\mathrm{PhD}$ dissertation, University of Pennsylvania. Online: https://www.ling.upenn.edu/ laurel/MacKenzie_dissertation.pdf

Meyerhoff, Miriam, \& Walker, James A. (2007). The persistence of variation in individual grammars: Copula absence in 'urban sojourners' and their stay-at-home peers, Bequia (St Vincent and the Grenadines). Journal of Sociolinguistics 11:346-366.

Nagy, Naomi, \& Irwin, Patricia. (2010). Boston (r): Neighbo(r)s nea(r) and fa(r). Language Variation and Change 22:241-278.

Phillips, Jock, \& Hearn, Terry (2013). Settlers: New Zealand immigrants from England, Ireland and Scotland 1800-1945. Auckland University Press.

R Core Team. (2019). R: A language and environment for statistical computing, vers. 3.6.1. Online: https://www.R-project.org/

Sankoff, David, \& Labov, William. (1979). On the uses of variable rules. Language in Society 8:189222.

Smith-Rosenberg, Carroll (1975). The female world of love and ritual: Relations between women in nineteenth-century America. Signs: Journal of Women in Culture and Society 1:1-29.

Tamminga, Meredith, MacKenzie, Laurel, \& Embick, David. (2016). The dynamics of variation in individuals. Linguistic variation 16:300-336.

Villarreal, Dan, Clark, Lynn, Hay, Jennifer, \& Watson, Kevin. (2020). From categories to gradience: Auto-coding sociophonetic variation with random forests. Laboratory Phonology 11(6). 1-31.

Weinreich, Uriel, Labov, William, \& Herzog, Marvin I. (1968). Empirical foundations for a theory of language change. In W. P. Lehmann \& Y. Malkiel (Eds.), Directions for historical linguistics. Austin: University of Texas Press. 97-195.

Wells, John C. (1982). Accents of English. Cambridge, UK: Cambridge University Press.

Wolfram, Walt, \& Schilling-Estes, Natalie. (2006). American speech, 2nd edition. Malden, MA: Blackwell.

Wright, Marvin N., \& Ziegler, Andreas. (2017). ranger: A fast implementation of random forests for high dimensional data in C ++ and R. Journal of Statistical Software 77:1-17.

OTHER RESOURCES REFERENCED

Southland Oral History Project: https://ilibrary.co.nz/research-archives/oral-history/ 